\title{
Translating Cholesterol Guidelines Into Primary Care Practice: A Multimodal Cluster Randomized Trial
}

\author{
Charles B. Eaton, $M D, M S^{1,2,3}$ \\ Donna R. Parker, ScD $D^{1,2}$ \\ Jeffrey Borkan, $M D^{1,2}$ \\ Jerome McMurray, MS ${ }^{2}$ \\ Mary B. Roberts, $M S^{2}$ \\ Bing Lu, DrPH \\ Roberta Goldman, $\mathrm{PbD}^{1,2}$ \\ David K. Abern, PbD $D^{5,6}$
}

'Department of Family Medicine, Alpert Medical School of Brown University,

Providence, Rhode Island

${ }^{2}$ Center for Primary Care and Prevention Memorial Hospital of Rhode Island,

Pawtucket, Rhode Island

${ }^{3}$ Department of Epidemiology, Alpert Medical School of Brown University, Providence, Rhode Island

${ }^{4}$ Division of Rheumatology, Immunology and Allergy, Brigham and Women's Hospital, Boston, Massachusetts

${ }^{5}$ Abacus Management Technologies LLC, Cranston, Rhode Island

${ }^{6}$ Program in Behavioral Informatics and eHealth, Brigham \& Women's Hospital, Harvard Medical School, Boston, Massachusetts

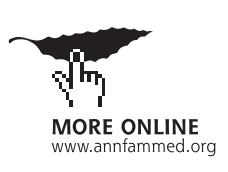

Conflicts of interest: HeartAge ${ }^{\circledR}$ is trademarked by Memorial Hospital of Rhode Island with Drs. Eaton and Abern as co-developers. All authors named above do not bave any potential conflicts.

\section{CORRESPONDING AUTHOR}

Charles B. Eaton, MD, MS

Center for Primary Care and Prevention

Memorial Hospital of Rhode Island

111 Brewster St

Pawtucket, RI 02860

Charles_Eaton@mhri.org

\begin{abstract}
PURPOSE We wanted to determine whether an intervention based on patient activation and a physician decision support tool was more effective than usual care for improving adherence to National Cholesterol Education Program guidelines.

METHODS A 1-year cluster randomized controlled trial was performed using 30 primary care practices (4,105 patients) in southeastern New England. The main outcome was the percentage of patients screened for hyperlipidemia and treated to their low-density lipoprotein (LDL) and non-high-density lipoprotein (HDL) cholesterol goals.
\end{abstract}

RESULTS After 1 year of intervention, both randomized practice groups improved screening (89\% screened), and $74 \%$ of patients in both groups were at their LDL and non-HDL cholesterol goals $(P<.001)$. Using intent-to-treat analysis, we found no statistically significant differences between practice groups in screening or percentage of patients who achieved LDL and non-HDL cholesterol goals. Post hoc analysis showed practices who made high use of the patient activation kiosk were more likely to have patients screened (odds ratio $[\mathrm{OR}]=2.54 ; 95 \%$ confidence interval $[\mathrm{Cl}], 1.97-3.27)$ compared with those who made infrequent or no use. Additionally, physicians who made high use of decision support tools were more likely to have their patients at their LDL cholesterol goals (OR $=1.27 ; 95 \%$ $\mathrm{Cl}, 1.07-1.50)$ and non-HDL goals (OR $=1.23 ; 95 \% \mathrm{Cl}, 1.04-1.46)$ than low-use or no-use physicians.

CONCLUSION This study showed null results with the intent-to-treat analysis regarding the benefits of a patient activation and a decision support tool in improving cholesterol management in primary care practices. Post hoc analysis showed a potential benefit in practices that used the e-health tools more frequently in screening and management of dyslipidemia. Further research on how to incorporate and increase adoption of user-friendly, patient-centered e-health tools to improve screening and management of chronic diseases and their risk factors is warranted.

Ann Fam Med 2011;9:528-537. doi:10.1370/afm.1297.

\section{INTRODUCTION}
C
oronary heart disease (CHD) remains the leading cause of death in the United States and in most Western countries.' Strong evidence linking hyperlipidemia to CHD and the clinical benefits of medical therapy in the treatment of hyperlipidemia led to evidence-based consensus guidelines regarding the optimal management of hyperlipidemia for the United States, the National Cholesterol Education Program (NCEP) Adult Treatment Panel (ATP) III Cholesterol Management Guidelines. Despite the publication of these guidelines in 2001 and an update in $2004,{ }^{2,3}$ there continues to be large variations in clinical practice, ${ }^{4,5}$ and it is estimated that 40 million Americans have hyperlipidemia treated suboptimally. ${ }^{6}$ 
This problem of underscreening and undertreatment of dyslipidemia is also true for Canada, Britain, Australia, and other European Union countries. ${ }^{7-14}$ Potential barriers to the implementation of cholesterol guidelines into clinical practice appear related to clinician knowledge, attitudes, and behaviors; patient knowledge, attitudes, and behaviors; doctor-patient communication issues; and system-based issues, such as economics and the lack of organized systems of care around the recognition and treatment of hyperlipidemia. ${ }^{15-17}$ Thus a multimodal approach affecting clinicians, patients, doctor-patient communication, and office systems (clinical decision support tools, patient education materials, office waiting room computer kiosks) is likely to be needed to translate these guidelines into clinical practice.

Emerging interactive technologies (ie, Internet, computer kiosks, Internet-enabled cell phones, personal digital assistants (PDAs), and more recently tablet computers provide the opportunity to catalyze these interactions through increasingly sophisticated and individually tailored programs. ${ }^{18}$ Based upon an adaptation of the Chronic Care Model, ${ }^{19}$ we hypothesized that patients interacting with a tailored computer program located in their doctor's waiting room regarding their individual risk of a heart attack would be informed and activated. The informed, activated patients would advocate for lipid screening if they were not aware of their cholesterol values by asking for these results, or they would be more receptive to engaging in a dialog with their physicians regarding optimal hyperlipidemia management. We also postulated that providing a PDA-based decision support program to primary care physicians would allow them to equip a prepared, proactive team that would foster optimal lipid management. Thus the convergence of the activated, informed patient and the prepared, proactive team should result in improvement in ATP III cholesterol guideline adherence and improved numbers of patients at their respective low-density lipoprotein (LDL) cholesterol and non-high-density lipoprotein (HDL) cholesterol goals.

\section{METHODS}

\section{Study Design and Data Collection}

This randomized cluster trial was aimed at testing a multimodal intervention designed to increase the screening and management of hyperlipidemic patients according to the NCEP 2001 ATP III cholesterol treatment guidelines in primary care practices. Thirty representative primary care physician practices in Southeastern New England involving 55 primary care physicians and 4,105 patients were recruited and are reported on in this study. The data for these analyses came from medical record chart reviews, telephone interviews with patients, and in-person questionnaires and interviews with physicians. The research and Health Insurance Probability and Accountability Act ${ }^{20}$ protocol of physicians, staff, and patients were approved by the human subjects protection committee Institutional Review Board of Memorial Hospital of Rhode Island. A cluster-randomized trial design was chosen because the focus of the intervention was at the practice level and involved clinician screening and management of hyperlipidemia in the context of the clinical care. Practices were block randomized by size, specialty, and percentage of patients at LDL goal.

\section{Intervention}

Between October 2004 and May 2005, all practices received a 1 -hour academic detailing session during which ATP III cholesterol guidelines were discussed and abbreviated guideline pocket guides were given to each physician before the random allocation process. After the random allocation process, intervention practices received a patient education toolkit, a computer kiosk with patient activation software, and a personal digital assistant (PDA)-based decision support tool for each physician, which included 4 booster academic detailing sessions. Control practices received a PDA but without the decision support tool and had minimal further contact to mimic usual care.

The academic detailing consisted of a PowerPoint slide presentation of the ATP III cholesterol guidelines, reprints of the ATP III guidelines, and National Heart, Lung Blood Institute ATP IIII pocket guides. Booster academic detailing sessions for the intervention practices consisted of a review of new clinical trial evidence regarding lipid management and coronary heart disease, updated guidelines, barriers and facilitators of the use of the physician PDA decision support tool, the patient activation tool, and the use of the patient education toolkits.

The patient education toolkit consisted of smoking cessation, weight loss, healthy diets, exercise, and lipidlowering medication adherence materials, which were given to each intervention practice. A companion Web site was developed to download these materials and to allow patients or physicians to recalculate the patient's HeartAge ${ }^{21}$ after initial determination and management, if desired.

\section{Patient Activation Tool}

The patient activation tool, HeartAge, ${ }^{21}$ was developed using focus groups and an interactive cycle of feedback and usability testing to provide a motivating metaphor for patients to understand the risk associated 
with high-LDL cholesterol levels and low-HDL cholesterol levels and having a coronary event. Using touch screen technology, patients answered questions regarding their risk factors for coronary heart disease (age, sex, blood pressure, total and HDL cholesterol levels, diabetes) into a computerized kiosk. The subsequent 10 -year CHD risk was calculated and then converted into the average age of an individual in the Framingham Heart Study of the same sex. Thus, a male patient aged 56 years with a 24\% 10 -year risk of CHD was told they had the HeartAge of an 80 year old. Patients who did not know their cholesterol levels or blood pressure numbers were prompted to ask their physician or practice staff to inform them of these numbers so they could calculate their HeartAge (Figure 1).
$90 \%$ and was monitored on a $10 \%$ duplicate sampling for quality control during the practice reauditing. Any disagreement on the major outcome, LDL cholesterol values, and non-HDL cholesterol values was reviewed by one of the investigators (D.R.P., C.B.E.) who were blinded to the physician and practice, and a final decision was made. Data on a patient's medical history, history of cardiovascular disease, lipid disorder, hypertension, weight, diabetes mellitus, and smoking management was collected from the patient's medical records. Baseline assessment was based upon the medical record from the previous 5 years (1999 through 2004) for lipid values, CHD risk factors, comorbid conditions, and medication use. No adverse events attributable to the study protocol were ascertained from the chart audits.

\section{Physician PDA Decision Support Tool}

The physicians were given a PDA with interactive decision support software. This software determined the patient's lipid diagnosis (LDL dominant, isolated low HDL level, triglyceride dominant, mixed lipid disorder, and atherogenic dyslipidemia), calculated the ATP III LDL and non-HDL cholesterol goals (when appropriate), made recommendations regarding therapeutic lifestyle management, provided optimal dosage of lipidlowering drugs tailored to the patient's risk factor status to meet the ATP III goals, and provided an interactive shared decisionmaking page for physicians to discuss lowering lipid values in the context of HeartAge, absolute and relative risks, and other $\mathrm{CHD}$ risk factor management (Figure 2). A simple survey on the PDA assessed the impact of the tool on the physician's decision making.

\section{Outcome Assessment (Chart Audits)}

Between June 2003 and May 2005 baseline data were collected from the office medical records by trained abstractors. Postintervention data were collected from October 2005 through June 2006. Test-retest and between-abstractors reliability was greater than

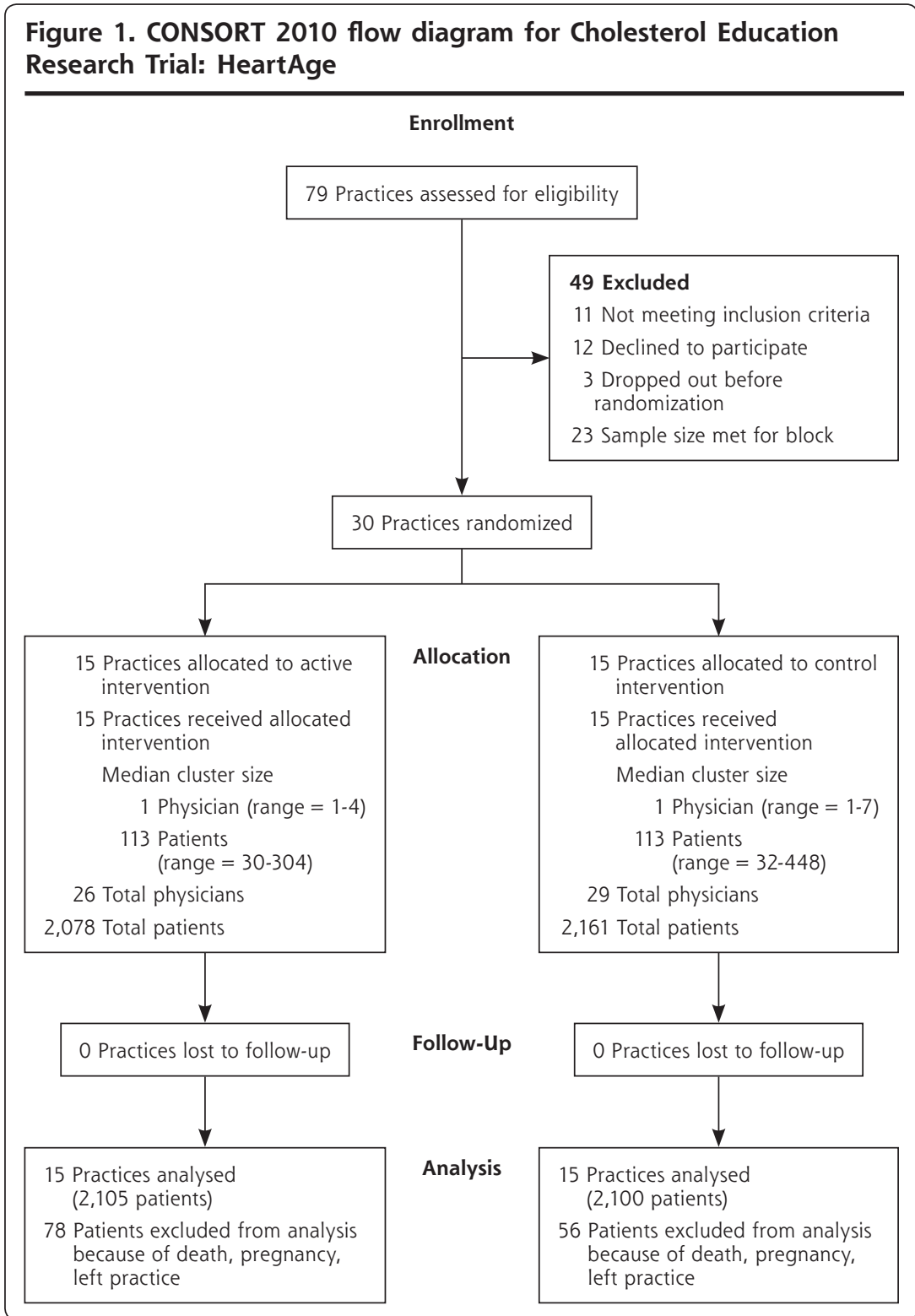




\section{Figure 2. Patient-activation tool to calculate HeartAge.}
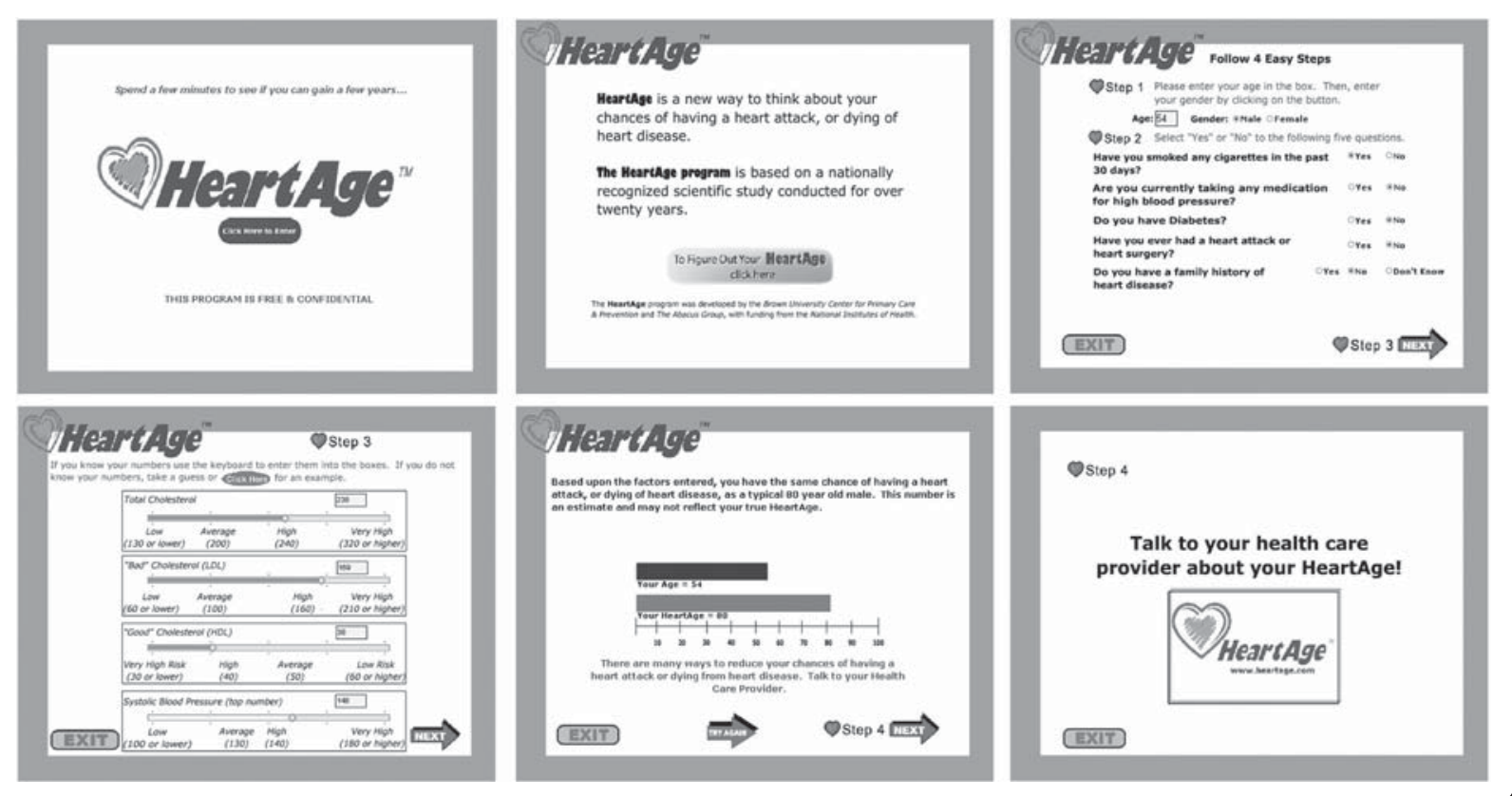

\section{Measurements and Categorization}

ATP III Cholesterol Guideline Adherence

Patients at baseline were grouped into 4 categories of CHD risk ${ }^{2}$ based upon the 2001 ATP III guidelines: (1) $1 \mathrm{CHD}$ risk factor $=$ low risk; $;$ (2) 2 or more risk factors but a less than $10 \% 10$-year risk of $\mathrm{CHD}=$ moderate risk; (3) 2 or more risk factors and a $10 \%$ to $20 \%$ 10-year risk of $\mathrm{CHD})=$ high-risk ; and (4) diabetes, coronary heart disease, or $20 \%$ or greater 10 -year risk of $\mathrm{CHD}=$ extremely high risk or CHD equivalent . Further details regarding LDL and non-HDL cholesterol goals for each of the 4 categories are included in Sup-

plemental Appendix 1 (http://www.annfammed.

각 org/content/9/6/528/suppl/DC1).

\section{Statistical Analysis}

The primary outcome for this trial was the proportion of patients screened and treated according to the 2001 NCEP guidelines to their LDL and non-HDL cholesterol goals within 1 year of the intervention. The analyses for this study take into account the clustering of patients within practices, but the actual outcomes were individual patients within practices. Because physicians may share patient management within a practice, we did not analyze clustering by physician.

Physician-, practice-, and patient-level characteristics were compared by intervention arm using appropriate descriptive statistics. Least squares means adjusting for clustering was used to define the descriptive characteristics of the study participants, so that the overall average values are not just the mean of the intervention and control participants.

We performed both an intent-to-treat and post hoc compliance analyses to account for differential adoption of the intervention tools in the practices randomized to the intervention. A generalized linear mixed model for binary outcomes to account for clustering with time, intervention group, time-by-group interactions as a function of LDL and non-HDL cholesterol goal attainment was performed in the intent-to-treat analysis. Additional patient- and practice-level covariates were balanced between intervention and control practices, so no additional covariates were placed in the models. We applied the last value carried forward method for missing data. For the post hoc analysis, we added a PDA use variable to the model to evaluate LDL and non-HDL cholesterol goal attainment; for kiosk use for lipid-screening evaluation, we used the PROC GLIMMX (SAS 9.2, SAS Institute, Cary, North Carolina) procedure. $P<.05$ was used to determine statistical significance.

Our sample size of 30 practices was determined based upon a baseline assessment of $60 \%$ at their LDL cholesterol goal, $80 \%$ power, and a treatment effect of $10 \%$, assuming 56 patients per practice and an intraclass cluster coefficient (ICC) of 0.0256 .

\section{RESULTS}

Of 79 practices assessed for eligibility, 49 were excluded, and the remaining 30 practices were divided equally 
Figure 3. Example of a patient's calculated HeartAge.

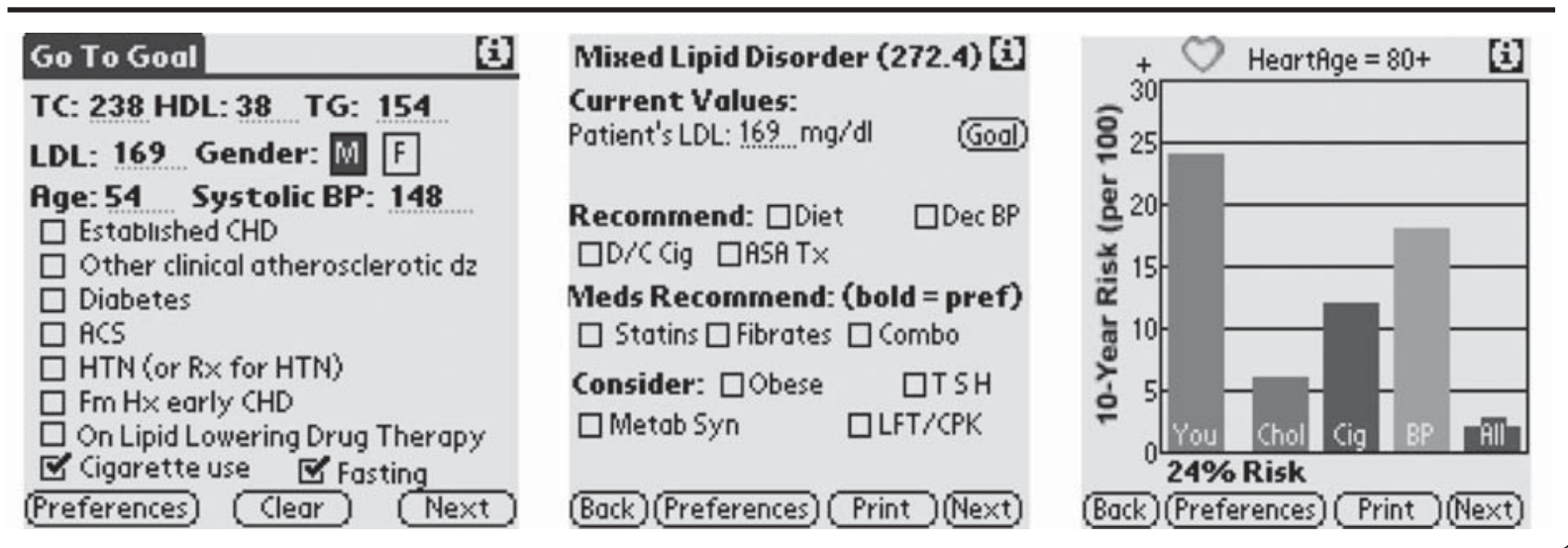

into the control and intervention groups. Details of practice and patient recruitment and randomization are given in a Supplemental Appendix 2 (http://www. annfammed.org/content/9/6/528/

קil suppl/DC1) and CONSORT diagram, Figure 1.

Baseline characteristics of practices, physicians, and patients in the intervention and control practices are displayed in Table 1. Intervention and control practices, physicians, and patients were similar regarding all analyzed characteristics except that the control practices had a slighter greater percentage of patients with moderate CHD risk.

\section{Patient Activation and Physician Use of a Decision Support Tool}

The patient activation kiosk was used on 12,617 visits (range $=21$ to 1,787 ) by the 15 intervention practices. Using this kiosk, HeartAge was calculated 4,000 times (39\% completion rate) ${ }_{i}$ however, all patients using the kiosk were prompted to ask their physician for their cholesterol levels if they could not calculate their HeartAge. Median use was 75 times per 1,000 patients per practice.

The 32 primary care physicians in the intervention practices made 4,756 entries for PDA decision support tool use, with a range of use of 22 to 631 logins per physician. Median use was 95 entries per physician. Physicians were surveyed regarding how the tool affected their decision making on 1,389 logins. The physicians reported that the tool changed their rec-

\section{Table 1. Baseline Characteristics of Patients in Cholesterol} Education and Research Trial

\begin{tabular}{|c|c|c|c|}
\hline Characteristic & Control & Intervention & $P$ Value \\
\hline Practices, No. & 15 & 15 & \\
\hline \multicolumn{4}{|l|}{ Size, No. (\%) } \\
\hline Solo & $8(53)$ & $9(60)$ & 0.71 \\
\hline Group & $7(47)$ & $6(40)$ & \\
\hline $\begin{array}{l}\text { Nurse practitioner/physician's } \\
\text { assistant in practice, No. (\%) }\end{array}$ & $5(33)$ & $7(47)$ & 0.46 \\
\hline \multicolumn{4}{|l|}{ Type, No. (\%) } \\
\hline Family practice & $8(53)$ & $7(47)$ & 0.72 \\
\hline Internal medicine & $7(47)$ & $8(53)$ & \\
\hline Hospital affiliated (n, \%) & $2(13)$ & $3(20)$ & 1.00 \\
\hline Physicians, No. & 29 & 26 & \\
\hline Age, mean (SD), y & $46.7(6.3)$ & $46.4(8.4)$ & 0.94 \\
\hline Male, No. (\%) & $22(76)$ & $16(62)$ & 0.25 \\
\hline Years in practice, mean (SD) & $15.8(6.9)$ & $15.0(8.8)$ & 0.95 \\
\hline $\begin{array}{l}\text { Patients seen per week, mean } \\
\text { (SD), No. }\end{array}$ & $99(46)$ & $96(28)$ & 0.39 \\
\hline Never used PDA, No. (\%) & $11(38)$ & $13(50)$ & 0.21 \\
\hline $\begin{array}{l}\text { Minutes behind at the end } \\
\text { of the day, mean (SD), No. }\end{array}$ & $18(14.1)$ & $23(21.5)$ & 0.46 \\
\hline Patients, No. ${ }^{a}$ & 2,105 & 2,000 & \\
\hline Male, \% & 41.8 & 39.7 & 0.69 \\
\hline \multicolumn{4}{|l|}{ Marital status, $\%$} \\
\hline Partnered & 71.0 & 72.3 & 0.53 \\
\hline Not partnered & 29.0 & 27.7 & \\
\hline \multicolumn{4}{|l|}{ Race, \% } \\
\hline American Indian & 0.5 & 0.5 & 0.61 \\
\hline Asian & 0.8 & 0.7 & \\
\hline African American & 1.2 & 1.3 & \\
\hline White & 95.7 & 95.8 & \\
\hline Hispanic & 1.7 & 1.3 & \\
\hline Missing & 0.3 & 0.2 & \\
\hline \multicolumn{4}{|l|}{ CHD risk group, $\%$} \\
\hline CHD equivalent & 18.4 & 21.1 & 0.33 \\
\hline High & 9.8 & 9.2 & 0.73 \\
\hline Moderate & 24.6 & 17.5 & 0.02 \\
\hline \multirow[t]{2}{*}{ Low } & 44.4 & 50.4 & 0.25 \\
\hline & & & continued \\
\hline
\end{tabular}


ommendations $27 \%$ of the time, and $55 \%$ of the time it changed the patient's behavior.

\section{Intent-to-Treat Analysis}

After 1 year of intervention, there were strong secular trends, with both randomized groups improving screening $(89 \%)$ and the percentage of patients at their LDL (74\%) and non-HDL cholesterol goals (74\%) $(P<.001)$. There was no statistically significant difference between the intervention and control groups over time in screening or guideline-appropriate treatment (Figure 4). The ICCs for the percentage at their LDL cholesterol goal was ICC $=0.019$ (95\% confidence interval [CI]), 0.009-0.038); for the percentage at their non-HDL cholesterol goal was ICC $=0.018$ (95\% CI, $0.009-0.036) ;$ and for the percentage screened was ICC $=0.06$ (95\% CI, 0.035-0.098). In addition, no statistically significant findings were found in any CHD risk category subgroup to the overall results.

\section{Post Hoc Analysis}

Post hoc analysis showed that practices with abovemedian use of the patient activation kiosk were more likely to have patients screened with a full lipid profile (odds ratio $[\mathrm{OR}]=2.54 ; 95 \% \mathrm{CI}, 1.97-3.27$ ) than those with infrequent or no use. Physicians with abovemedian use of the PDA decision support tool were more likely to have their patients at LDL cholesterol goals $(\mathrm{OR}=1.27 ; 95 \% \mathrm{CI}, 1.07-1.50)$ and non-HDL cholesterol goals $(\mathrm{OR}=1.23 ; 95 \% \mathrm{CI}, 1.04-1.46)$ than physicians with below-median or no PDA use. A sensitivity analysis using updated 2004 ATP III thresholds for cholesterol management showed attenuated improvement in attaining goals by frequent users of the PDA decision support tool, with patients reaching LDL cholesterol goals more frequently at $16 \%$ of the time $(\mathrm{OR}=1.16 ; 95 \% \mathrm{CI}, 0.98-1.36)$ and non-HDL cholesterol goals more frequently at $12 \%$ of the time $(\mathrm{OR}=1.12 ; 95 \% \mathrm{CI}, 0.95-1.32)$.

We also examined whether there was a

Table 1. Baseline Characteristics of Patients in Cholesterol Education and Research Trial (continued)

\begin{tabular}{|c|c|c|c|}
\hline Characteristic & Control & Intervention & $P$ Value \\
\hline Patients, No. ${ }^{a}$ & 2,105 & 2,000 & \\
\hline Current smoker, \% & 13.8 & 10.8 & 0.21 \\
\hline Physically inactive, \% & 24.7 & 23.4 & 0.63 \\
\hline At LDL cholesterol goal (\%) & 58.9 & 58.4 & 0.89 \\
\hline At non-HDL cholesterol goal, \% & 62.3 & 65.5 & 0.33 \\
\hline $\begin{array}{l}\text { Diagnosed lipid disorder treated } \\
\text { with lipid medications, \% }\end{array}$ & 56.1 & 57.3 & 0.74 \\
\hline $\begin{array}{l}\text { Treatment gap for lipid manage- } \\
\text { ment, \% }\end{array}$ & 29.3 & 30.6 & 0.74 \\
\hline \multicolumn{4}{|l|}{ Medical history, \% } \\
\hline COPD & 7.6 & 5.9 & 0.40 \\
\hline Diabetes & 9.6 & 11.2 & 0.27 \\
\hline Hypertension & 45.6 & 41.9 & 0.40 \\
\hline Undiagnosed hypertension & 3.2 & 3.0 & 0.80 \\
\hline Controlled hypertension & 82.3 & 82.8 & 0.88 \\
\hline Lipid disorder & 59.2 & 56.9 & 0.67 \\
\hline Undiagnosed lipid disorder & 17.6 & 19.0 & 0.71 \\
\hline Overweight & 5.9 & 8.1 & 0.31 \\
\hline Obese & 17.1 & 17.5 & 0.91 \\
\hline Depression & 25.8 & 25.6 & 0.96 \\
\hline GERD & 20.7 & 22.7 & 0.51 \\
\hline Metabolic syndrome & 0.7 & 1.6 & 0.18 \\
\hline Family history of CHD & 38.4 & 30.2 & 0.35 \\
\hline $\begin{array}{l}\text { Living with } 2 \text { or more chronic } \\
\text { conditions }\end{array}$ & 58.2 & 56.8 & 0.78 \\
\hline Age, mean (SE), y & $52.3(1.1)$ & $54.0(1.1)$ & 0.25 \\
\hline $\begin{array}{l}\text { Total cholesterol, mean (SE), } \\
\text { mg/dL }\end{array}$ & $193(1.8)$ & $193(1.8)$ & 0.88 \\
\hline LDL cholesterol, mean (SE), mg/dL & $114(1.6)$ & $114(1.5)$ & 0.96 \\
\hline HDL cholesterol, mean (SE), mg/dL & $54(0.9)$ & $54(0.9)$ & 0.53 \\
\hline $\begin{array}{l}\text { Prescription drugs, mean (SE), } \\
\text { No. }\end{array}$ & $4.8(1.1)$ & $4.7(1.1)$ & 0.86 \\
\hline $\begin{array}{l}\text { Chronic conditions, mean (SE), } \\
\text { No. }\end{array}$ & $2.0(1.1)$ & $1.9(1.1)$ & 0.76 \\
\hline
\end{tabular}
difference by sex in response to the intervention, as women have been reported to be underscreened and undertreated for dyslipidemia. ${ }^{22}$ After adjusting for risk category, no clinically significant differences were found in goal attainment by sex.

\section{DISCUSSION}

This study of a multimodal approach to guideline implementation regarding cholesterol management in primary care practice produced null results with the intentto-treat analysis. The post hoc analysis appeared more promising and may show benefit regarding screening and improved LDL and non-HDL cholesterol goal attainment in response to the increased use of the patient activation tool, which used a cardiovascular age metaphor, HeartAge, to describe the patient's CHD risk.

There may be several plausible reasons for this null result, including strong secular trends, a ceiling effect on the intervention resulting from high levels of screening and treatment in the selected physicians and patients, not targeting the intervention to high-risk groups that would benefit the most from the intervention, lack of intervention efficacy because inadequate design (academic detailing, patient activation, physician decision support tool, and a physician tool kit are not optimal interventions), inadequate dose of the interven- 
Figure 4. LDL (A) and HDL (B) cholesterol goals over time by risk and treatment group.

A. LDL Cholesterol Goal Over Time by Risk and Treatment Group

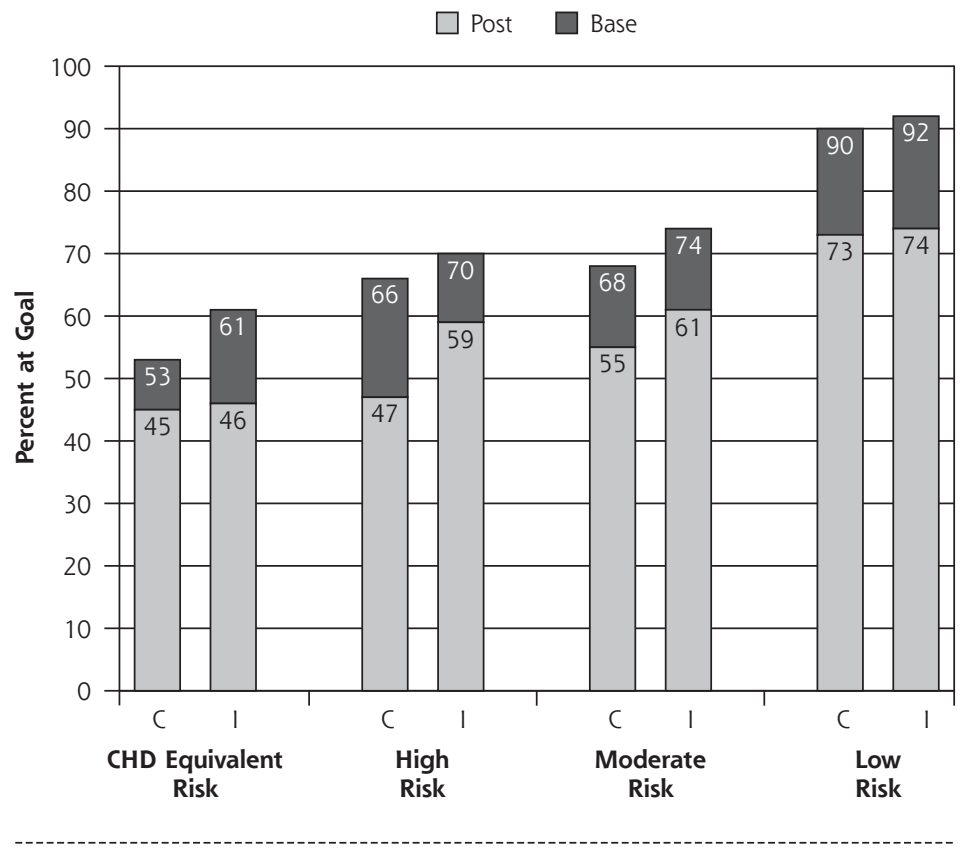

B. Non-HDL Cholesterol Goal Over Time by Risk and Treatment Group

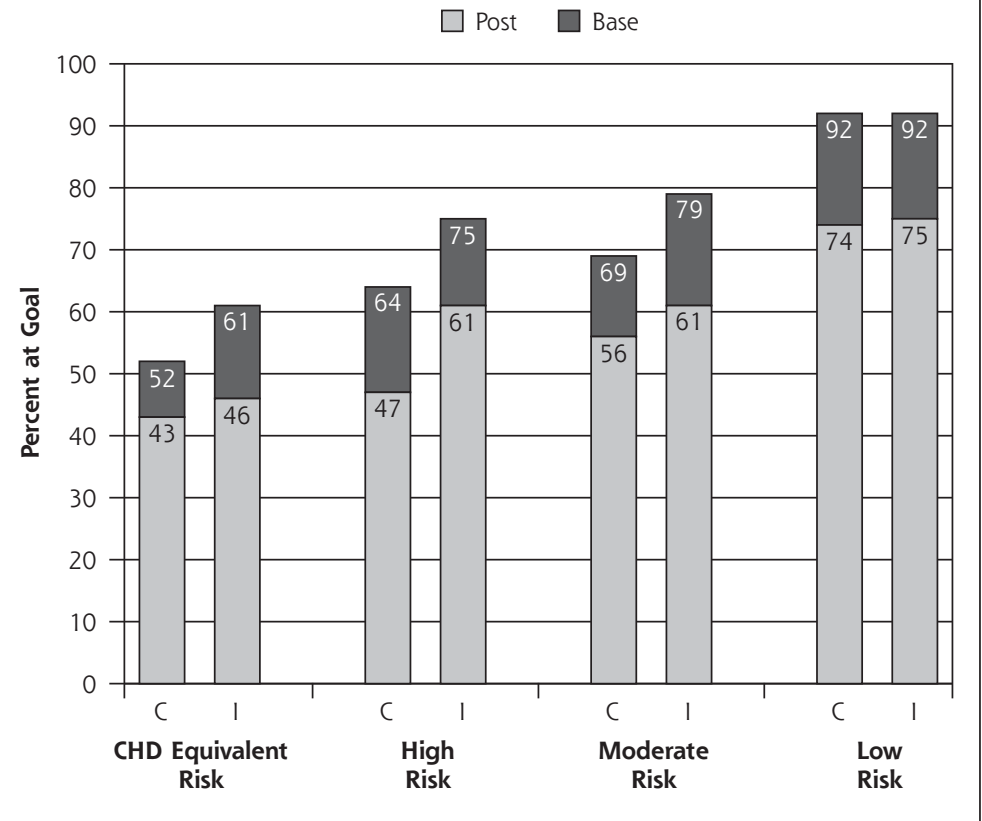

$\mathrm{C}=$ control, $\mathrm{CHD}=$ coronary heart disease $\mathrm{HDL}=$ high-density lipoprotein, I = intervention, $\mathrm{LDL}=$ low-density lipoprotein.

Note: total numbers for the study groups for each risk level are as follows: CHD equivalent risk: control base $=368$, follow-up $=425$, and intervention base $=405$, follow-up $=450$; high risk: control base $=213$, follow-up $=248$, and intervention base $=180$, follow-up $=208$; moderate risk: control base $=475$, follow-up $=536$, and intervention base $=360$, follow-up $=448$; low risk: control base $=1,049$, follow-up $=896$, and intervention base $=1,055$, follow-up $=894$. Changes in the numbers from baseline to follow-up are related to the accumulation of additional risk factors over the year of follow-up. tion (ie, tools not adequately adopted by practices), misclassification of the outcomes caused by inaccuracy of chart audits, and selected dropout of patients in follow-up, or chance. During the time of this study, there was a marked increase in direct-to-consumer advertising of statins and the publication of several important studies including the Heart Protection Study, ${ }^{23}$ PROSPER, ${ }^{26}$ ASCOT-LLA, ${ }^{25}$ and PROVE-IT, ${ }^{26}$ which likely contributed to the strong secular trend found in this study. A pilot study that used the same sampling method 2 years earlier had lower rates of screening and percentage of patients at their respective LDL and non-HDL cholesterol goals. ${ }^{30}$

Consistent with our post-hoc analysis of the potential benefits of using a cardiovascular age metaphor in the patient activation and physician decision support tools, Grover et al in the Check-UP Study, ${ }_{1}^{14}$ evaluating dyslipidemic patients in primary care practices, found improved cholesterol management using a predicted age gap patient education tool. In the Grover et al study, physicians compared the patient's riskfactor-adjusted age with the patient's chronological age and found that an increase in the predicted age gap was associated with the increased likelihood that the patient reached their cholesterol-lowering goals. In our study, physicians reported that the PDA decision support tool with its shared decisionmaking page incorporating HeartAge lead to more changes in patient behavior than changes in physician behavior, adding credence to the hypothesis that a predicted age gap metaphor might be helpful in motivating patients to accept lipid-lowering therapy.

Other studies assessing a variety of implementation strategies for improving cholesterol management in the primary care setting have shown mixed results. ${ }^{27-29}$ The GLAD heart study ${ }^{27}$ evaluated ATP III guideline implementation in the primary care setting in North Carolina using an interactive PDA decision support tool and academic detailing during the same period 
as our study. Bertoni et $\mathrm{al}^{27}$ found minimal change in the intervention practices and worsening of cholesterol management in the control practices, with the difference reaching statistical significance. Using electronic health records and quarterly performance reporting for 21 quality indicators that included hyperlipidemia, Ornstein et $\mathrm{al}^{28}$ tested the effect of academic detailing on quality improvement and automated audit and feedback performance. Regarding hyperlipidemia screening and management within the context of coronary heart disease and diabetes, they found no benefit using this approach. Lester et $\mathrm{al}_{,}{ }^{29}$ in a pilot study using an e-mail flagging system within an electronic health record, found increases in statin-prescribing behavior after 1 month, which persisted for 1 year.

Our study has several strengths and limitations that should be considered when interpreting the results. First, although the primary care physicians in this study were not a random sample, they represented a reasonable cross-section of primary care physicians in southeastern New England, albeit perhaps more prevention-oriented than the average community practitioner. Compared with all primary care physicians in our catchment area, our study practitioners were similar regarding their age, sex, and years in practice.

For many variables, such as smoking status and race/ethnicity, we had both medical record audits and patient self-reported data to improve the accuracy of reporting. The patients who agreed to participate in this study might not represent the entire primary care patient population but may represent those with an increased interest in coronary heart disease risk factor reduction. In a separate subsample of practices $(\mathrm{n}=4)$, we compared random de-identified chart audits $(\mathrm{n}=350)$ with our identified chart audits $(\mathrm{n}=236){ }^{30}$ The 2 samples were similar with respect to age, marital status, prescription benefits, frequency of hypertension, diabetes, lipid disorders, and being in the extremely high CHD risk-equivalent category, but the recruited patients were less likely to be smokers, more likely to be in the high-risk and low-risk categories, and less likely to be in the moderate CHD risk category.

The internal validity or lack of confounding bias of our study should be considered high because of the randomization process used in the intent-to-treat analysis. The post hoc analysis with its statistically significant findings, however, may be subject to confounding bias and therefore should be interpreted with caution. It may be that practices with increased kiosk use had characteristics other than patient activation that may explain the enhanced screening behavior at the practice. Similarly, physicians who were high users of the PDA decision support tool may have had characteristics other than increased PDA use that may explain the increased LDL and non-HDL cholesterol goal attainment of their patients. An analysis of such potential factors showed only that low users of the PDA tool reported being behind by an average of 45 minutes at the end of the day compared with 15 minutes for high users of the PDA tool $(P<.001)$.

During the past decade a great deal of quality improvement and guideline implementation research has been performed regarding other CHD risk factors, including smoking cessation, ${ }_{1}^{31-34}$ physical activity, ${ }^{35,36}$ weight loss for obesity, ${ }_{1}^{37-39}$ hypertension control, ${ }^{40-42}$ and diabetes control, ${ }^{43-45}$ that may inform future research on where efforts for improved cholesterol management should be focused. We believe that by using the lessons learned from our study and the implications from other CHD risk factor studies, we can make the following recommendations.

Given the high rates of screening found in this and other recent studies, ${ }^{5,6,30}$ most adult patients who see primary care physicians regularly are screened for lipid disorders. Efforts to improve screening in the practice should focus on increasing the reach of interventions using the list of patients who are not regularly seen; similarly, efforts should be made to promote screening in work sites or community centers.

Providing patient activation tools appears promising in promoting self-care and shared decision making, but they need user-friendly interfaces and must deal with innumeracy, health literacy, and cultural values of the patients to be effective. ${ }^{45-48}$ Tailoring these tools to specific audiences and finding the appropriate channels-print, telephones, smartphone applications, computer kiosk, or Internet-appears to be important. . $^{31-38,46,50,51}$

Clinical decision support tools are promising but need to be user friendly and fit into the physician's workflow or a become part of an office system team effort. ${ }^{18,19,30,43,45}$ Despite our attempt to create a userfriendly interface for our PDA decision support tool and the addition of a guideline adherence feature and a shared decision-making page, uptake was modest. We can see a potential benefit when this tool fits into the physician's workflow, as was shown by the greaterthan-median use. With the advent of electronic health records, disease registries, and patient-centered medical homes (with a team-based practice redesign that includes care managers, clinical pharmacists, group visits, etc), opportunities arise to use clinical decision support tools more effectively. For example, studies have shown that a team-based approach improved cholesterol management, blood pressure control, and diabetes control. ${ }^{40-43,45}$ Other studies have suggested that integration with the larger community resources is also effective. ${ }^{52}$ 
In summary, a well-designed multimodal practice guideline implementation study in primary care practice showed no benefit to the intervention and found a strong secular trend of increased cholesterol screening and goal attainment.

Post hoc analysis showed some potential benefit from the use of patient activation and physician decision support using a shared decision-making tool to improve cholesterol screening and management in primary care practices. Further research on how to use behavioral science and informatics principles to simultaneously empower patients and support physicians with decision support tools is warranted. The potential is great for further development, adoption, and evaluation of user-centered health information technology tools and resources in the primary care setting to improve quality of care for a variety of prevention and chronic disease management challenges.

To read or post commentaries in response to this article, see it online at http://www.annfammed.org/content/9/6/528.

Key words: Hyperlipidemia; e-health; implementation science

Submitted February 17, 2011; submitted, revised, May 25, 2011; accepted June 8, 2011.

Acknowledgements: All the research assistants and staff at the Center for Primary Care and Prevention, Abacus Technologies, and the 30 primary care practices and their patients made this trial possible.

\section{References}

1. Rosamond W, Klegal K, Friday G, et al. Heart disease and stroke statistics, 2007 update: a report from the American Heart Association Statistics Committee and Stroke Statistics Subcommittee. Circula tion. 2007;115: e69-e171.

2. US Department of Health and Human Services; National Institutes of Health; National Heart Lung and Blood Institute. Third Report of the National Cholesterol Education Program (NCEP) Expert Panel on Detection, Evaluation and Treatment of High Blood Cholesterol in Adults (Adult Treatment Panel III) Final Report. Heart Lung and Blood Institute, NIH Publication No. 02-5125; 2002.

3. Grundy SM, Cleeman JI, Merz LN. Heart, Lung and Blood Institute; American College of Cardiology Foundation; American Heart Association. Implications of recent clinical trials for the National Cholesterol Program Adults Treatment Panel III Guidelines. Circulation. 2004;110(2)227-239.

4. Pearson TA, Laurora I, Chu H, Kafonek S. The lipid treatment assessment project (L-TAP): a multicenter survey to evaluate the percentages of dyslipidemic patients receiving lipid-lowering therapy and achieving low-density lipoprotein cholesterol goals. Arch Intern Med. 2000;160(4):459-467.

5. Bertoni AG, Bonds DE, Steffes S, et al. Quality of cholesterol screening and management with respect to the National Cholesterol Education's Third Adult Treatment Panel (ATP III) guideline in primary care practices in North Carolina. Am Heart J. 2006;152(4):785-792.

6. Keevil JG, Cullen MW, Gangnon R, McBride PE, Stein JH. Implications of cardiac risk and low-density lipoprotein cholesterol distribution in the United States for the diagnosis and treatment of dyslipidemia: Data from National Health and Nutrition Examination Survey 1999 to 2002. Circulation. 2007;115(11):1363-1370.
7. Atella V, Brady A, Catapano AL, et al. Bridging science and health policy in cardiovascular disease: focus on lipid management: a report from a session held during the 7th International Symposium on Multiple Risk Factors in Cardiovascular Diseases: Prevention and Intervention-Health Policy. Venice, Italy, 25 Oct 2008. Atheroscler Suppl. 2009;10(1):3-21.

8. EUROASPIRE Study Group. A European Society of Cardiology survey of secondary prevention of coronary heart disease: principal results. European action on secondary prevention through intervention to reduce events. Eur Heart J. 1997;18(10):1569-1582.

9. EUROASPIRE II Study Group. Lifestyle and risk factor management and use of drug therapies in coronary patients from 15 countries; principal results from EUROASPIRE II Euro Heart Survey Programme. Eur Heart J. 2001;22(7):554-572.

10. EUROASPIRE III survey. European Heart Survey on Secondary and Primary Prevention of Coronary Heart Disease. www.escardio.org/ guidelines-surveys/ehs/prevention/pages/eurospire3-survey.aspx. Accessed Jan 15, 2009

11. García Ruiz FJ, Marín Ibáñez A, Pérez-Jiménez F, et al; REALITY Study Group. Current lipid management and low cholesterol goal attainment in common daily practice in Spain. The REALITY Study. Pharmacoeconomics. 2004;22(Suppl 3):1-12.

12. Chen L, Rogers SL, Colagiuri S, et al. How do the Australian guidelines for lipid-lowering drugs perform in practice? Cardiovascular disease risk in the AusDiab Study, 1999-2000. Med J Aust. 2008;189(6):319-322.

13. Jaussi A, Noll G, Meier B, Darioli R. Current cardiovascular risk management patterns with special focus on lipid lowering in daily practice in Switzerland. Eur J Cardiovasc Prev Rehabil. 2010;17(3): 363-372.

14. Grover SA, Lowensteyn I, Joseph L, et al; Cardiovascular Health Evaluation to Improve Compliance and Knowledge Among Uninformed Patients (CHECK-UP) Study Group. Patient knowledge of coronary risk profile improves the effectiveness of dyslipidemia therapy: the CHECK-UP study: a randomized controlled trial. Arch Intern Med. 2007;167(21):2296-2303.

15. Hobbs FD, Erhardt L. Acceptance of guideline recommendations and perceived implementation of coronary heart disease prevention among primary care physicians in five European countries: the Reassessing European Attitudes about Cardiovascular Treatment (REACT) survey. Fam Pract. 2002;19(6):596-604.

16. Eaton CB, Galliher JM, McBride PE, Bonham AJ, Kappus JA, Hickner J. Family physician's knowledge, beliefs, and self-reported practice patterns regarding hyperlipidemia: a National Research Network (NRN) survey. J Am Board Fam Med. 2006;19(1):46-53.

17. Parker DR, Gramling R, Goldman RE, et al. Physicians' perceptions of barriers and facilitators regarding adoption of the National Cholesterol Education Program guidelines. Prev Cardiol. 2008;11(1):29-35.

18. Ahern DK. Challenges and opportunities of eHealth research. Am J Prev Med. 2007;32(5)(Suppl):S75-S82.

19. Bodenheimer T, Wagner EH, Grumbach K. Improving primary care for patients with chronic illness. JAMA. 2002;288(14):1775-1779.

20. Department of Health and Human Services. 45 CVR Parts 160 and 164-Standards for Privacy of Individually Identifiable Health Information; Final rule, December 28, 2000. http://aspe.hhs.gov/ admnsimp/final/PvcFR01.pdf. Accessed Aug 19, 2010.

21. Goldman RE, Parker DR, Eaton CB, et al. Patients' perceptions of cholesterol, cardiovascular disease risk, and risk communication strategies. Ann Fam Med. 2006;4(3):205-212.

22. Kim C, Hofer TP, Kerr EA. Review of evidence and explanations for suboptimal screening and treatment of dyslipidemia in women. A conceptual model. J Gen Intern Med. 2003;18(10):854-863.

23. Heart Protection Study Collaborative Group. MRC/BHF Heart Protection Study of cholesterol lowering with simvastatin in 20,536 high-risk individuals: a randomised placebo-controlled trial. Lancet. 2002;360(9326):7-22. 
24. Shepherd J, Blauw GJ, Murphy MB, et al. Pravastatin in elderly individuals at risk of vascular disease (PROSPER): a randomized controlled trial. PROspective Study of Pravastatin in the Elderly at Risk. Lancet. 2002;360(9346):1623-1630.

25. Sever PS, Dahlöf B, Poulter NR, et al; ASCOT investigators. Prevention of coronary and stroke events with atorvastatin in hypertensive patients who have average or lower-than-average cholesterol concentrations, in the Anglo-Scandinavian Cardiac Outcomes Trial-Lipid Lowering Arm (ASCOT-LLA): a multicentre randomised controlled trial. Lancet. 2003;361(9364):1149-1158.

26. Cannon CP, Braunwald E, McCabe $\mathrm{CH}$, et al; Pravastatin or Atorvastatin Evaluation and Infection Therapy-Thrombolysis in Myocardial Infarction 22 Investigators. Intensive versus moderate lipid lowering with statins after acute coronary syndromes. N Engl J Med. 2004;350(15):1495-1504.

27. Bertoni $A G$, Bonds $D E$, Chen $\mathrm{H}$, et al. Impact of a multifaceted intervention on cholesterol management in primary care practices: guideline adherence for heart health randomized trial. Arch Intern Med. 2009;169(7):678-686

28. Ornstein $S$, Jenkins RG, Nietert PJ, et al. A multi-method quality improvement intervention to improve preventive cardiovascular care. Ann Intern Med. 2004;141(7):523-532.

29. Lester WT, Grant RW, Barnett GO, Chueh HC. Randomized controlled trial of an informatics-based intervention to increase statin prescription for secondary prevention of coronary disease. J Gen Intern Med. 2006;21(1):22-29.

30. Eaton CB, Parker DR, Craft J, et al. Using e-health to improve cholesterol management in primary care practice. J Med Pract Manage. 2009;24(4):224-230.

31. Lenert L, Muñoz RF, Stoddard J, et al. Design and pilot evaluation of an internet smoking cessation program. J Am Med Inform Assoc. 2003;10(1):16-20.

32. Rimer BK, Orleans CT, Fleisher $\mathrm{L}$, et al. Does tailoring matter? The impact of a tailored guide on ratings and short-term smoking-related outcomes for older smokers. Health Educ Res. 1994;9(1):69-84.

33. Velicer WF, Prochaska JO, Redding CA. Tailored communications for smoking cessation: past successes and future directions. Drug Alcohol Rev. 2006;25(1):49-57.

34. Velicer WF, Prochaska JO, Fava JL, Laforge RG, Rossi JS. Interactive versus noninteractive interventions and dose-response relationships for stage-matched smoking cessation programs in a managed care setting. Health Psychol. 1999;18(1):21-28.

35. Marcus BH, Bock BC, Pinto BM, Forsyth LH, Roberts MB, Traficante RM. Efficacy of an individualized, motivationally-tailored physical activity intervention. Ann Behav Med. 1998;20(3):174-180.

36. Marshall AL, Leslie ER, Bauman AE, Marcus BH, Owen N. Print versus website physical activity programs: a randomized trial. Am J Prev Med. 2003;25(2):88-94.

37. Patrick K, Raab F, Adams MA, et al. A text message-based interven tion for weight loss: randomized controlled trial. J Med Internet Res. 2009;11(1):e1.
38. Tate DF, Jackvony EH, Wing RR. Effects of Internet behavioral counseling on weight loss in adults at risk for type 2 diabetes: a randomized trial. JAMA. 2003;289(14):1833-1836.

39. Womble LG, Wadden TA, McGuckin BG, Sargent SL, Rothman RA, Krauthamer-Ewing ES. A randomized controlled trial of a commercial internet weight loss program. Obes Res. 2004;12(6):1011-1018.

40. Carter BL, Rogers M, Daly J, Zheng S, James PA. The potency of team-based care interventions for hypertension: a meta-analysis. Arch Intern Med. 2009;169(19):1748-1755.

41. Bogden PE, Abbott RD, Williamson P, Onopa JK, Koontz LM. Comparing standard care with a physician and pharmacist team approach for uncontrolled hypertension. J Gen Intern Med. 1998; 13(11):740-745

42. Zillich AJ, Sutherland JM, Kumbera PA, Carter BL. Hypertension outcomes through blood pressure monitoring and evaluation by pharmacists (HOME study). J Gen Intern Med. 2005;20(12):1091-1096.

43. Nutting PA, Dickinson WP, Dickinson LM, et al. Use of chronic care model elements is associated with higher-quality care for diabetes. Ann Fam Med. 2007;5(1):14-20.

44. Meigs JB, Cagliero E, Dubey A, et al. A controlled trial of webbased diabetes disease management: the MGH diabetes primary care improvement project. Diabetes Care. 2003;26(3):750-757.

45. Martin OJ, Wu WC, Taveira TH, Eaton CB, Sharma SC. Multidis ciplinary group behavioral and pharmacologic intervention for cardiac risk reduction in diabetes: a pilot study. Diabetes Educ. 2007;33(1):118-127.

46. Ahern DH, Woods SS, Lighttower MC, Finley SW, Huston TK. Promise of and potential for patient-facing technologies to enable meaningful use. Am J Prev Med. 2011;40(5S2):S162-\$172.

47. Clark N, Becker M, Janz N, et al. Self-management of chronic disease by older adults: a review and questions for research. J Aging Health. 1991;3(1):3-27.

48. Lorig $K R$, Sobel DS, Stewart AL, et al. Evidence suggesting that a chronic disease self-management program can improve health status while reducing hospitalization: a randomized trial. Med Care. 1999;37(1):5-14.

49. Bodenheimer T, Lorig KR, Holman H, Grumbach K. Patient selfmanagement of chronic disease in primary care. JAMA. 2002;288 (19):2469-2475.

50. Noar SM, Benac CN, Harris MS. Does tailoring matter? Meta-analytic review of tailored print health behavior change interventions. Psychol Bull. 2007;133(4):673-693.

51. Williams D, Matthews C, Rutt C, Napoitano M, Marcus B. Interventions to increase walking behavior. Med Sci Sports Exerc. 2008;40(7 Suppl):S5670S573.

52. Woolf SH, Glasgow RE, Krist A, et al. Putting it together: finding success in behavior change through integration of services. Ann Fam Med. 2005;3(Suppl 2):S20-S27. 